(c) American Dairy Science Association, 2004.

\title{
Microbial Counts, Fermentation Products, and Aerobic Stability of Whole Crop Corn and a Total Mixed Ration Ensiled With and Without Inoculation of Lactobacillus casei or Lactobacillus buchneri
}

\author{
N. Nishino, ${ }^{1}$ H. Wada, ${ }^{1}$ M. Yoshida, ${ }^{2}$ and H. Shiota ${ }^{2}$ \\ ${ }^{1}$ Department of Animal Science, Faculty of Agriculture, Okayama University, Okayama 700-8530, Japan \\ ${ }^{2}$ Futaba Feed Ltd., Seto-cho, Okayama 709-0841, Japan
}

\begin{abstract}
Whole crop corn (DM 29.2\%) and a total mixed ration (TMR, DM 56.8\%) containing wet brewers grains, alfalfa hay, dried beet pulp, cracked corn, soybean meal, and molasses at a ratio of 5:1:1:1:1:1 on fresh weight basis, were ensiled with and without Lactobacillus casei or Lactobacillus buchneri in laboratory silos. The effects of inoculation on microbial counts, fermentation products, and aerobic stability were determined after 10 and $60 \mathrm{~d}$. Untreated corn silage was well preserved with high lactic acid content, whereas large numbers of remaining yeasts resulted in low stability on exposure to air. Inoculation with $L$. casei suppressed heterolactic fermentation, but no improvements were found in aerobic stability. The addition of $L$. buchneri markedly enhanced the aerobic stability, while not affecting the DM loss and $\mathrm{NH}_{3}-\mathrm{N}$ production. Large amounts of ethanol were found when the TMR was ensiled, and the content of ethanol overwhelmed that of lactic acid in untreated silage. This fermentation was related to high yeast populations and accounted for a large loss of DM found in the initial $10 \mathrm{~d}$. The ethanol production decreased when inoculated with $L$. casei and L. buchneri, but the effects diminished at $60 \mathrm{~d}$ of ensiling. Inoculation with $L$. buchneri lowered the yeasts in TMR silage from the beginning of storage; however, the populations decreased to undetectable levels when stored for $60 \mathrm{~d}$, regardless of inoculation. No heating was observed in TMR silage during aerobic deterioration test for $7 \mathrm{~d}$. This stability was achieved even when a high population of yeasts remained and was not affected by either inoculation or ensiling period. The results indicate that inoculation with $L$. buchneri can inhibit yeast growth and improve aerobic stability of corn and TMR silage; however, high stability of TMR silage can be obtained
\end{abstract}

Received July 10, 2003.

Accepted September 26, 2003.

Corresponding author: N. Nishino; e-mail: jloufeed@cc.okayamau.ac.jp. even when no treatments were made and high population $\left(>10^{5} \mathrm{cfu} / \mathrm{g}\right)$ of yeasts were detected.

(Key words: aerobic stability, lactic acid bacteria, silage, total mixed ration)

Abbreviation key: LAB = lactic acid bacteria.

\section{INTRODUCTION}

Many types of homofermentative lactic acid bacteria (LAB) have been commercially prepared as silage additives. Those selected strains can encourage rapid $\mathrm{pH}$ decline and inhibit DM loss and clostridial fermentation, thereby improving preservation in a silo. Aerobic stability of silage, however, will be lowered by inoculation with homofermentative LAB, because antimycotic VFA are lowered and lactic acid is easily oxidized by aerobic microorganisms (McDonald et al., 1991). The spoilage process is usually initiated by yeasts, thereby silages with high yeast population were reported to be unstable on exposure to air (Hara et al., 1979; Woolford, 1990).

Recently, a considerable amount of research has been carried out on the use of Lactobacillus buchneri as an alternative inoculant (Driehuis et al., 1999, 2002; Weinberg et al., 1999, 2002; Ranjit and Kung, 2000; Kung and Ranjit, 2001; Ranjit et al., 2002; Taylor et al., 2002). The addition of this heterofermentative LAB inhibits yeast growth both during ensiling and after exposure to air (Driehuis et al., 1999). Aerobic stability is thus considerably enhanced, and the silage could remain unheated as long as $30 \mathrm{~d}$ (Driehuis et al., 1999). It has been demonstrated that L. buchneri can convert lactic acid into acetic acid and 1,2-propanediol anaerobically (Oude Elferink et al., 2001). This metabolic activity was shown to increase when ensiling was prolonged (Driehuis et al., 1999), indicating that improved stability would be distinct after storage for several months. It has also been demonstrated that Lactobacillus diolivorans can further metabolize 1,2-propanediol into propionic acid and 1-propanol (Krooneman et al., 2002); however, the degradation is not concrete, and occasion- 
ally 1,2-propanediol accumulated as much as 5\% DM (Nishino et al., 2003a).

It has become a common practice in Japan that ensiling high-moisture by-products with dry feeds as a TMR. This can alleviate the labor prior to feeding rations and may help efficient use of unpalatable or nutritionally unbalanced by-products. Nishino et al. (2003b) reported that, although ensiled wet brewers grains spoils readily after unloading, considerable stability was found when brewers grains were stored as a low-moisture (approximately DM 55\%) TMR silage. Yeast population decreased as the storage was prolonged, whereas associate changes were not clearly found in fermentation products. It was concluded that high concentrations of undissociated acids could account for the stability (Nishino et al., 2003b); however, L. buchneri was isolated as a dominant LAB and small amount of 1,2propanediol was detected in similar TMR silages. One of the isolated strains has been shown to inhibit aerobic deterioration of corn silage (Nishino et al., 2003a), suggesting that $L$. buchneri might be involved in the stability of TMR silage.

The objectives of this study are to ascertain the relevance of $L$. buchneri in the stability of TMR silage, and to compare the effects of this heterofermentative LAB in the storage of whole crop corn and low-moisture mixed by-products. Silos were opened after 10 and 60 $\mathrm{d}$, because short storage is favored in commercial TMR silages. Silages inoculated with $L$. casei were prepared as negative controls in terms of aerobic stability. The use of $L$. case $i$ was also aimed at excluding the activity of $L$. buchneri in the ensiling of TMR mixture.

\section{MATERIALS AND METHODS}

\section{Inoculants}

Lactobacillus casei and L. buchneri were isolated from a commercial inoculant and a TMR silage, respectively (Nishino et al., 2003a). Pure cultures of the bacteria were made in MRS (de Man, Rogosa, Sharpe) broth (Oxoid CM359, Basingstoke, England) at $30^{\circ} \mathrm{C}$ for 24 $\mathrm{h}$, and inocula were prepared by 2 -fold dilution of the cultures with sterile physiological saline. The inocula were sprayed onto the materials at $2.0 \mathrm{~mL} / \mathrm{kg}$. The LAB populations inoculated by $L$. casei and $L$. buchneri were calculated to be $2 \times 10^{6}$ and $1 \times 10^{6} \mathrm{cfu} / \mathrm{g}$ for corn, and $3 \times 10^{6}$ and $1 \times 10^{6} \mathrm{cfu} / \mathrm{g}$ for TMR mixture, respectively. Levels of $L$. case $i$ were different between the 2 materials, while the cultures were made in the same conditions. Uncultured MRS broth diluted in the same way was used as the control inoculum.

\section{Ensiling}

Whole crop corn and a TMR were used as silage materials. Corn was harvested with a precision chop harvester at the stage of half milk-line, and $380 \mathrm{~g}$ was ensiled in polyethylene bottles (500-mL capacity) with and without LAB inoculation. Total mixed ration was formulated with wet brewers grains, alfalfa hay, dried beet pulp, cracked corn, soybean meal, and molasses at a ratio of 5:1:1:1:1:1 on fresh weight basis. From a $20-\mathrm{kg}$ batch of the TMR mixture, samples of $480 \mathrm{~g}$ were taken and ensiled in the same way as described in corn ensiling. Wet brewers grains were obtained from a local brewing factory and subjected to silage preparation within $12 \mathrm{~h}$ of production. Alfalfa hay, dried beet pulp, and cracked corn were lacerated to small particles to ensure complete mixing of the 6 ingredients. The densities of ensiled material were 760 and $960 \mathrm{~kg} / \mathrm{m}^{3}$ for corn and TMR silage, respectively. Silos were capped with gas-releasable Bunsen bulbs and stored for 10 and 60 $\mathrm{d}$ at $25^{\circ} \mathrm{C}$. Treatments were made in triplicate.

\section{Chemical and Microbial Analyses}

The DM of materials and silages were determined by freeze-drying, and lyophilized powders were used to determine total N, NDF, ADF, and soluble sugars. Total $\mathrm{N}$ was measured by the Kjeldahl procedure, and NDF and ADF (Van Soest et al., 1991) were expressed as ash-free forms. In the analysis of NDF, samples were boiled with heat stable $\alpha$-amylase, while sodium sulfite was not added. Soluble sugars were determined by HPLC. Isocratic analysis was made at $40^{\circ} \mathrm{C}$ on Asahipak NH2P-50 (Showa Denko, Tokyo, Japan), and sugars were detected by a differential refractometer (Shimadzu RID-10A, Kyoto, Japan). Acetonitrile/water (70:30, vol/vol) was used as the eluant and flow rate was set at $1 \mathrm{~mL} / \mathrm{min}$. Sample clean up was carried out by using a disposable cartridge column (Waters Seppak C18, Tokyo, Japan).

Fermentation products were measured on cold water extracts. A 20-g sample of silage was homogenized with $180 \mathrm{~mL}$ of distilled water, and the filtrate was used for $\mathrm{pH}$, lactic acid, and $\mathrm{NH}_{3}-\mathrm{N}$ analyses (Nishino et al., 1999). Volatile fatty acids and alcohols were determined by a GLC (Shimadzu GC-14A, Kyoto, Japan) fitted with a glass capillary column $(15 \times 0.53 \mathrm{~mm})$ coated with TCFFAP (GL Sciences, Tokyo, Japan). The temperature of column oven was programmed at $80^{\circ} \mathrm{C}$ for the first $2 \mathrm{~min}$ and thereafter increased to $200^{\circ} \mathrm{C}$ at a rate of $10^{\circ} \mathrm{C} / \mathrm{min}$.

The numbers of LAB and yeasts were counted by pour-plate technique in MRS agar and potato dextrose agar, respectively. The plates were incubated at $30^{\circ} \mathrm{C}$ for $3 \mathrm{~d}$. 
Table 1. Chemical and microbial composition of whole crop corn and TMR mixture. ${ }^{1}$

\begin{tabular}{lcc}
\hline & Whole crop corn & TMR mixture \\
\hline DM (\%) & 29.2 & 56.8 \\
CP (\% DM) & 6.56 & 19.2 \\
NDF (\% DM) & 51.8 & 30.5 \\
ADF (\% DM) & 30.5 & 15.4 \\
PH & 5.68 & 5.50 \\
Lactic acid bacteria (log cfu/g) & 5.64 & 6.52 \\
Yeast (log cfu/g) & 5.52 & 5.20 \\
Fructose (\% DM) & 2.46 & 2.37 \\
Glucose (\% DM) & 2.88 & 4.64 \\
Sucrose (\% DM) & 3.19 & 5.32 \\
Maltose (\% DM) & 0.00 & 2.31 \\
\hline
\end{tabular}

${ }^{1}$ Mean values of duplicate analysis.

\section{Aerobic Stability Test}

When the silo was opened, the content was thoroughly removed once. Then half the content was returned to the bottle, and a conventional thermometer was placed in the center of the silage. Bottles were kept in a room maintained at $25^{\circ} \mathrm{C}$, while the upper surface was uncovered and exposed to air. Changes in the temperature were recorded every $8 \mathrm{~h}$.

\section{Statistical Analysis}

Data were subjected to analysis of variance and statistical significance between means was determined by Tukey's multiple comparison. Differences were considered significant when probability was less than 0.05 .

\section{RESULTS}

The DM and sugar contents of corn and TMR mixture were 29.2 and $8.53 \% \mathrm{DM}$, and 56.8 and $14.6 \% \mathrm{DM}$, respectively (Table 1 ). The counts of epiphytic LAB and yeasts were both $>10^{5} \mathrm{cfu} / \mathrm{g}$ in the 2 materials.

Lactic acid production occurred rapidly in corn silage, and the contents reached about $7 \% \mathrm{DM}$ at $10 \mathrm{~d}$ with or without inoculation (Table 2). The addition of $L$. casei did not increase the production of lactic acid, while ammonia and mannitol were inhibited compared with untreated control. Inoculation with $L$. buchneri increased acetic acid and produced 1,2-propanediol at 1\% DM in 10-d silages. Yeasts were inhibited by this heterofermentative LAB, whereas in the other silages the counts seemed to be unchanged during the initial $10 \mathrm{~d}$. Soluble sugars completely disappeared when corn silage was inoculated with $L$. buchneri.

Except for inhibited deamination, benefits of $L$. casei were not shown even when ensilage was prolonged (Table 3). The effects of L. buchneri were, however, apparently enhanced in silage stored for $60 \mathrm{~d}$; lactic acid decreased and both acetic acid and 1,2-propanediol increased rather than in short storage. Yeasts were reduced to below the detectable level, and significant reduction in ethanol was found when $L$. buchneri was inoculated. Fructose and glucose disappeared at $60 \mathrm{~d}$ even in silages untreated and treated with $L$. casei.

Rapid lactic acid production was also found in TMR silage, although more ethanol than lactic acid was detected in untreated control (Table 4). At $10 \mathrm{~d}$ of ensiling, the amount of ethanol was over 4\% DM and the loss of DM was more than $10 \%$. The addition of $L$. casei improved the fermentation and the DM recovery of TMR silage; lactic acid was enhanced and, acetic acid, ethanol, ammonia, and DM loss were lowered. The numbers of LAB and yeasts were not affected by $L$. casei, and the yeasts were found to be more than $10^{6} \mathrm{cfu} / \mathrm{g}$ at 10 $\mathrm{d}$. The addition of $L$. buchneri also inhibited the ethanol production, whereas acetic acid increased and small

Table 2. Chemical and microbial composition of whole crop corn ensiled for $10 \mathrm{~d}$ with and without inoculation of Lactobacillus casei or Lactobacillus buchneri. ${ }^{1}$

\begin{tabular}{lcccc}
\hline Item & Control & L. casei & L. buchneri & SE \\
\hline DM (\%) & 28.1 & 28.1 & 28.0 & 0.31 \\
DM loss (\%) & 3.81 & 4.07 & 4.52 & 1.09 \\
PH & $3.68^{\mathrm{b}}$ & $3.71^{\mathrm{a}}$ & $3.71^{\mathrm{a}}$ & 0.01 \\
Lactic acid (\% DM) & 7.41 & 6.84 & 6.73 & 0.30 \\
Acetic acid (\% DM) & $1.60^{\mathrm{b}}$ & $1.09^{\mathrm{b}}$ & $2.68^{\mathrm{a}}$ & 0.14 \\
Ethanol (\% DM) & 0.32 & 0.61 & 0.38 & 0.09 \\
1,2-propanediol (\% DM) & $0.00^{\mathrm{b}}$ & $0.00^{\mathrm{b}}$ & $1.04^{\mathrm{a}}$ & 0.06 \\
Lactic acid bacteria (log cfu/g) & $8.05^{\mathrm{b}}$ & $7.38^{\mathrm{c}}$ & $8.89^{\mathrm{a}}$ & 0.27 \\
Yeast (log cfu/g) & $5.19^{\mathrm{a}}$ & $5.53^{\mathrm{a}}$ & $3.15^{\mathrm{b}}$ & 0.00 \\
NH $-\mathrm{N}(\% \mathrm{DM})$ & $0.04^{\mathrm{a}}$ & $0.03^{\mathrm{b}}$ & $0.04^{\mathrm{a}}$ & 0.06 \\
Fructose (\% DM) & $1.27^{\mathrm{a}}$ & $1.46^{\mathrm{a}}$ & $0.00^{\mathrm{b}}$ & 0.12 \\
Mannitol (\% DM) & $2.56^{\mathrm{a}}$ & $1.10^{\mathrm{b}}$ & $2.61^{\mathrm{a}}$ & 0.17 \\
Glucose $(\% \mathrm{DM})$ & $2.08^{\mathrm{a}}$ & $1.49^{\mathrm{a}}$ & $0.00^{\mathrm{b}}$ & \\
\hline
\end{tabular}

\footnotetext{
${ }^{1}$ Data are means of triplicate silages. Values in a same row with unlike superscript letters are significantly different $(P<0.05)$. Due to complete disappearance during storage, maltose and sucrose were not listed in this table.
} 
Table 3. Chemical and microbial composition of whole crop corn ensiled for $60 \mathrm{~d}$ with and without inoculation of Lactobacillus casei or Lactobacillus buchneri.

\begin{tabular}{lcccc}
\hline Item & Control & L. casei & L. buchneri & SE \\
\hline DM (\%) & 28.1 & 28.4 & 27.1 & 0.38 \\
DM loss (\%) & 4.21 & 3.38 & 8.08 & 1.32 \\
PH & $3.69^{\mathrm{b}}$ & $3.72^{\mathrm{b}}$ & $3.89^{\mathrm{a}}$ & 0.01 \\
Lactic acid (\% DM) & $6.11^{\mathrm{a}}$ & $6.93^{\mathrm{a}}$ & $3.73^{\mathrm{b}}$ & 0.40 \\
Acetic acid (\% DM) & $2.04^{\mathrm{b}}$ & $1.46^{\mathrm{b}}$ & $5.27^{\mathrm{a}}$ & 0.47 \\
Ethanol (\% DM) & $1.68^{\mathrm{a}}$ & $2.45^{\mathrm{a}}$ & $0.65^{\mathrm{b}}$ & 0.22 \\
1,2-propanediol (\% DM) & $0.00^{\mathrm{b}}$ & $0.00^{\mathrm{b}}$ & $2.80^{\mathrm{a}}$ & 0.53 \\
Lactic acid bacteria (log cfu/g) & $5.72^{\mathrm{b}}$ & $5.70^{\mathrm{b}}$ & $8.62^{\mathrm{a}}$ & 0.16 \\
Yeast (log cfu/g) & 5.81 & 5.62 & $<2.00$ & 0.00 \\
NH - $^{\mathrm{a}}(\% \mathrm{DM})$ & $0.05^{\mathrm{a}}$ & $0.04^{\mathrm{b}}$ & $0.06^{\mathrm{a}}$ & - \\
Fructose (\% DM) & 0.00 & 0.00 & 0.00 & 0.17 \\
Mannitol (\% DM) & 2.02 & 1.64 & 1.71 & - \\
Glucose (\% DM) & 0.00 & 0.00 & 0.00 & \\
\hline
\end{tabular}

\footnotetext{
${ }^{1}$ Data are means of triplicate silages. Values in a same row with unlike superscript letters are significantly different $(P<0.05)$. Due to complete disappearance during storage, maltose and sucrose were not listed in this table.
}

amount of 1,2-propanediol accumulated in TMR silage. The values of $\mathrm{pH}$ and $\mathrm{DM}$ loss were intermediate in silage treated with $L$. buchneri. The population of yeasts was lowered to about $10^{3} \mathrm{cfu} / \mathrm{g}$, and more mannitol was produced when $L$. buchneri was inoculated.

The profile of fermentation was almost unaffected by prolonged storage in the control TMR silage; ethanol was the highest to reach $4.7 \% \mathrm{DM}$, and DM loss attained as much as $12 \%$ (Table 5). Even in the control, yeasts were inhibited to below the detectable level, and a trace amount of 1,2-propanediol was determined at $60 \mathrm{~d}$. Although benefits of $L$. casei were found when storage was prolonged, significant improvements in the lactic acid, ethanol, and DM recovery diminished. Yeast population was greatly lowered at $60 \mathrm{~d}$, even in silage inoculated with $L$. casei. The effects of $L$. buchneri were fortified by prolonged ensiling and acetic acid and 1,2-pro- panediol increased. The production of ethanol appeared less in silage inoculated with $L$. buchneri, while the difference did not reach significance. Although ammonia content was similar at $10 \mathrm{~d}$ in silages between untreated and treated with $L$. buchneri, the values were higher in untreated control at $60 \mathrm{~d}$. The content of mannitol remained the highest when TMR mixture was inoculated with $L$. buchneri.

Although corn silage was prone to deteriorate in the presence of air, inoculation with $L$. buchneri greatly improved the stability regardless of the storage period (Figure 1). The 60-d silage treated with $L$. casei showed lower stability, and heating appeared earlier compared with the control. Aerobic stability was consistently high in TMR silage; no distinct heating was found during the 7-d test, and the stability was not affected by either inoculant or ensiling period.

Table 4. Chemical and microbial composition of TMR mixture ensiled for $10 \mathrm{~d}$ with and without inoculation of Lactobacillus casei or Lactobacillus buchneri. ${ }^{1}$

\begin{tabular}{|c|c|c|c|c|}
\hline Item & Control & L. casei & L. buchneri & SE \\
\hline $\mathrm{DM}(\%)$ & $52.2^{\mathrm{b}}$ & $55.4^{\mathrm{a}}$ & $53.4^{\mathrm{ab}}$ & 0.69 \\
\hline DM loss $(\%)$ & $11.3^{\mathrm{a}}$ & $4.91^{\mathrm{b}}$ & $8.45^{\mathrm{ab}}$ & 1.37 \\
\hline PH & $4.35^{\mathrm{a}}$ & $4.10^{\mathrm{c}}$ & $4.22^{\mathrm{b}}$ & 0.01 \\
\hline Lactic acid (\% DM) & $4.09^{b}$ & $5.29^{\mathrm{a}}$ & $4.40^{\mathrm{ab}}$ & 0.23 \\
\hline Acetic acid (\% DM) & $1.14^{\mathrm{b}}$ & $0.58^{\mathrm{c}}$ & $1.78^{\mathrm{a}}$ & 0.04 \\
\hline Ethanol (\% DM) & $4.43^{\mathrm{a}}$ & $2.42^{\mathrm{b}}$ & $2.69^{\mathrm{b}}$ & 0.16 \\
\hline 1,2-propanediol (\% DM) & $0.00^{\mathrm{b}}$ & $0.00^{\mathrm{b}}$ & $0.53^{\mathrm{a}}$ & 0.01 \\
\hline Lactic acid bacteria (log cfu/g) & $8.51^{\mathrm{b}}$ & $8.73^{\mathrm{b}}$ & $9.18^{\mathrm{a}}$ & 0.09 \\
\hline Yeast (log cfu/g) & $5.96^{\mathrm{a}}$ & $6.24^{\mathrm{a}}$ & $2.87^{\mathrm{b}}$ & 0.08 \\
\hline $\mathrm{NH}_{3}-\mathrm{N}(\% \mathrm{DM})$ & $0.05^{\mathrm{a}}$ & $0.03^{b}$ & $0.05^{\mathrm{a}}$ & 0.00 \\
\hline Fructose (\% DM) & $1.14^{\mathrm{b}}$ & $2.36^{\mathrm{a}}$ & $0.84^{\mathrm{b}}$ & 0.21 \\
\hline Mannitol (\% DM) & $2.16^{\mathrm{b}}$ & $0.91^{\mathrm{b}}$ & $3.60^{\mathrm{a}}$ & 0.33 \\
\hline Glucose (\% DM) & $1.87^{\mathrm{a}}$ & $2.96^{\mathrm{a}}$ & $0.00^{\mathrm{b}}$ & 0.26 \\
\hline
\end{tabular}

\footnotetext{
${ }^{1}$ Data are means of triplicate silages. Values in a same row with unlike superscript letters are significantly different $(P<0.05)$. Due to complete disappearance during storage, maltose and sucrose were not listed in this table.
} 
Table 5. Chemical and microbial composition of TMR mixture ensiled for $60 \mathrm{~d}$ with and without inoculation of Lactobacillus casei or Lactobacillus buchneri. ${ }^{1}$

\begin{tabular}{lcccc}
\hline Item & Control & L. casei & L. buchneri & SE \\
\hline DM (\%) & 51.9 & 53.2 & 53.3 & 0.36 \\
DM loss (\%) & 12.0 & 10.3 & 9.50 & 0.93 \\
PH & $4.23^{\mathrm{a}}$ & $4.07^{\mathrm{c}}$ & $4.17^{\mathrm{b}}$ & 0.01 \\
Lactic acid (\% DM) & $4.04^{\mathrm{ab}}$ & $5.01^{\mathrm{a}}$ & $3.72^{\mathrm{b}}$ & 0.09 \\
Acetic acid (\% DM) & $1.60^{\mathrm{b}}$ & $0.73^{\mathrm{c}}$ & $2.36^{\mathrm{a}}$ & 0.03 \\
Ethanol (\% DM) & 4.66 & 3.92 & 3.16 & 0.43 \\
1,2-propanediol (\% DM) & $0.29^{\mathrm{b}}$ & $0.00^{\mathrm{c}}$ & $0.96^{\mathrm{a}}$ & 0.06 \\
Lactic acid bacteria (log cfu/g) & 6.71 & $<4.00$ & 7.41 & - \\
Yeast (log cfu/g) & $<2.00$ & 2.91 & $<2.00$ & 0.00 \\
NH $_{3}$ (\% DM) & $0.09^{\mathrm{a}}$ & $0.04^{\mathrm{c}}$ & $0.07^{\mathrm{b}}$ & 0.06 \\
Fructose (\% DM) & $1.03^{\mathrm{b}}$ & $1.72^{\mathrm{a}}$ & $0.90^{\mathrm{b}}$ & 0.06 \\
Mannitol (\% DM) & $1.62^{\mathrm{b}}$ & $0.67^{\mathrm{c}}$ & $2.82^{\mathrm{a}}$ & 0.11 \\
Glucose (\% DM) & $0.00^{\mathrm{b}}$ & $2.62^{\mathrm{a}}$ & $0.00^{\mathrm{b}}$ &
\end{tabular}

${ }^{1}$ Data are means of triplicate silages. Values in a same row with unlike superscript letters are significantly different $(P<0.05)$. Due to complete disappearance during storage, maltose and sucrose were not listed in this table.

\section{DISCUSSION}

Typical fermentation and aerobic stability were found in untreated corn silage; lactic acid was produced intensively and the temperature was raised within $2 \mathrm{~d}$ after the silo was opened. Ensiling did not affect the population of yeasts, and more than $10^{5} \mathrm{cfu} / \mathrm{g}$ was counted at $10 \mathrm{~d}$ in the control silage. The production of mannitol implied that heterofermentative LAB was involved in the preservation of untreated silage, because mannitol can be formed from fructose due to the activity of several heterofermenters (McDonald et al., 1991)

The addition of $L$. casei did not improve the stability of corn silage on exposure to air, although the LAB could inhibit the deamination during ensiling. The lower stability at $60 \mathrm{~d}$ than control silage could be due to the differences, although not significant, in lactic and acetic acid between the 2 silages. During deterioration, aerobic microorganisms may increase when high lactic acid remained to support their energy consumption, whereas the growth would decrease when acetic acid accumulated to exhibit its antimycotic property (McDonald et al., 1991).

Inoculation with $L$. buchneri increased acetic acid and produced 1,2-propanediol in corn silage. The effects were greater when ensilage was prolonged, and $2.8 \%$ $\mathrm{DM}$ of 1,2-propanediol accumulated at $60 \mathrm{~d}$ of ensiling. It has been demonstrated that L. buchneri can metabolize lactic acid into acetic acid and 1,2-propanediol under anaerobic condition (Oude Elferink et al., 2001), and this activity may increase as the storage is prolonged (Driehuis et al., 1999). Nishino et al. (2003a) reported that, when corn silage was inoculated with the same L. buchneri as used in this study, 1,2-propanediol accumulated at 3.0 and $4.9 \% \mathrm{DM}$ after 60 and $120 \mathrm{~d}$ of storage, respectively. Further to the findings, the present experiments indicated that improved stability could be expected even when ensiling was short period and metabolites of $L$. buchneri were almost undetected.

The decrease in ethanol by L. buchneri was in good agreement with our previous study (Nishino et al., 2003a). Evidence has shown that L. buchneri produces a trace amount of ethanol in addition to acetic acid and 1,2-propanediol (Oude Elferink et al., 2001), and a number of research studies confirmed the increase in silage (Driehuis et al., 1999; Kung and Ranjit, 2001; Taylor et al., 2002). However, the contrasting results obtained in our experiments indicate that $L$. buchneri could decrease ethanol through inhibiting the activity of yeasts in silage.

Ethanol silage was produced when TMR mixture was ensiled without any treatments. Such fermentation was also reported with grass silages, particularly when lowmoisture and high-sugar material was ensiled (Driehuis and van Wikselaar, 2000). The DM and sugar contents of TMR mixture were 56.8 and $14.6 \%$ DM, respectively, thereby characteristics of ensiled material could agree with those reported. In this study, the ethanol fermentation appeared to be suppressed by L. casei and L. buchneri, suggesting that both heterofermentative $\mathrm{LAB}$ and yeasts were involved in the high production of ethanol. However, it is still difficult to define factors that could explain the ethanol production, because occasionally lactic acid dominated the fermentation in such low-moisture and high-sugar TMR silage (Nishino et al., 2003b).

The effects of $L$. buchneri on fermentation products appeared less in TMR than corn silage. This difference could be due to high DM in TMR mixture, because wilting was shown to suppress the production of 1,2propanediol by L. buchneri in Italian ryegrass and Fes- 


\section{Whole crop corn silage}

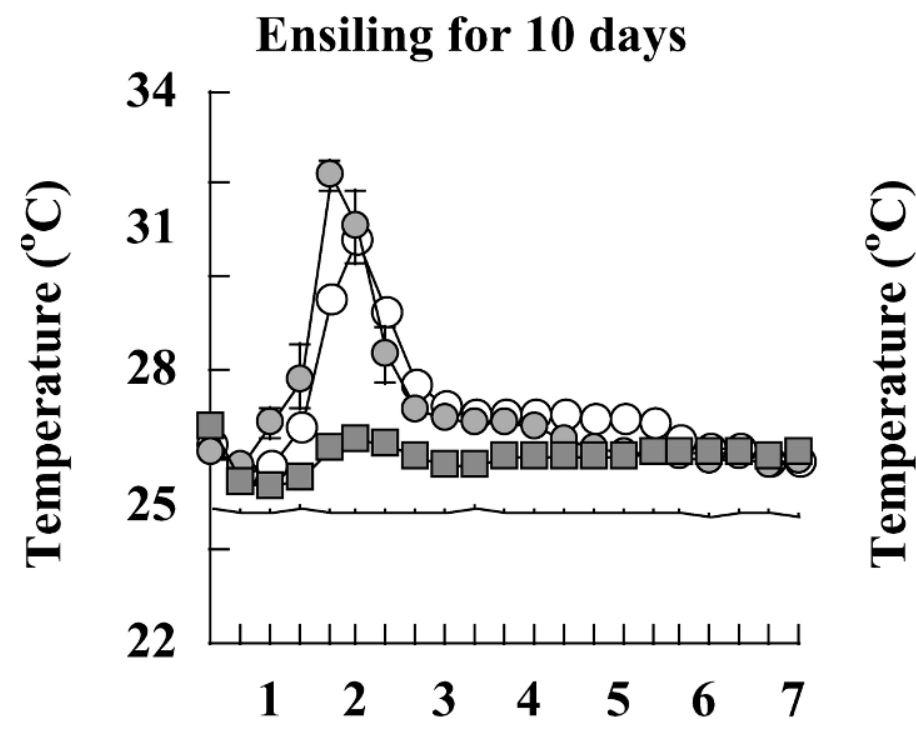

Days after aerobic exposure

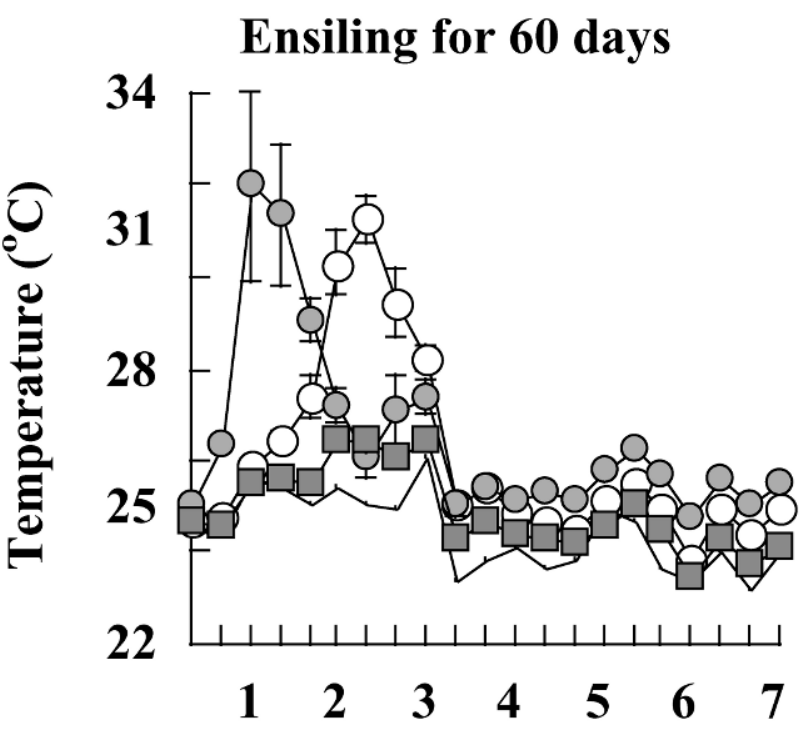

Days after aerobic exposure

\section{Total mixed ration silage}

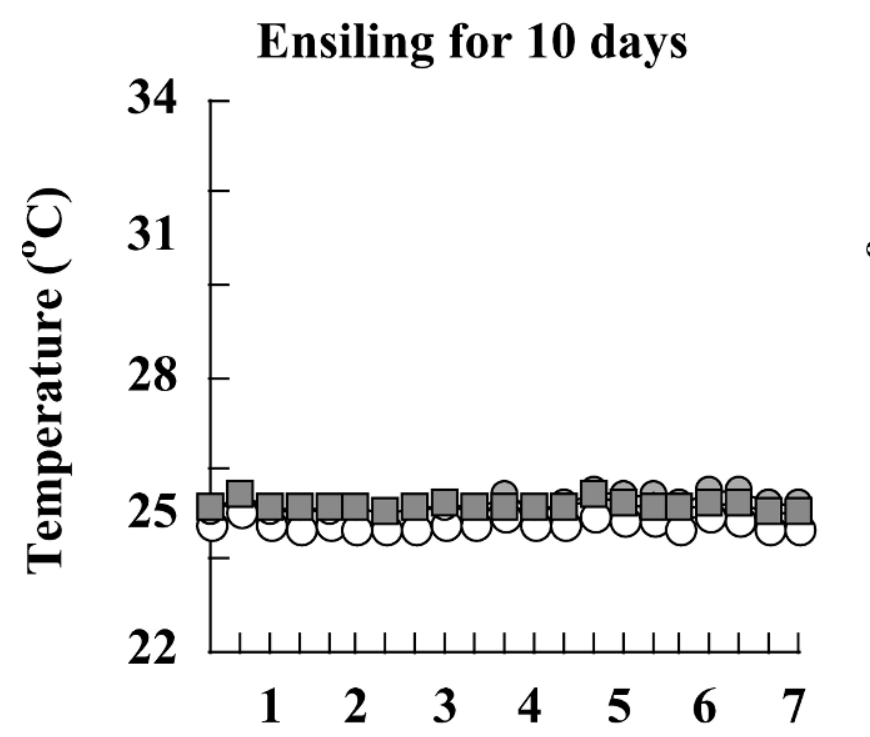

Days after aerobic exposure

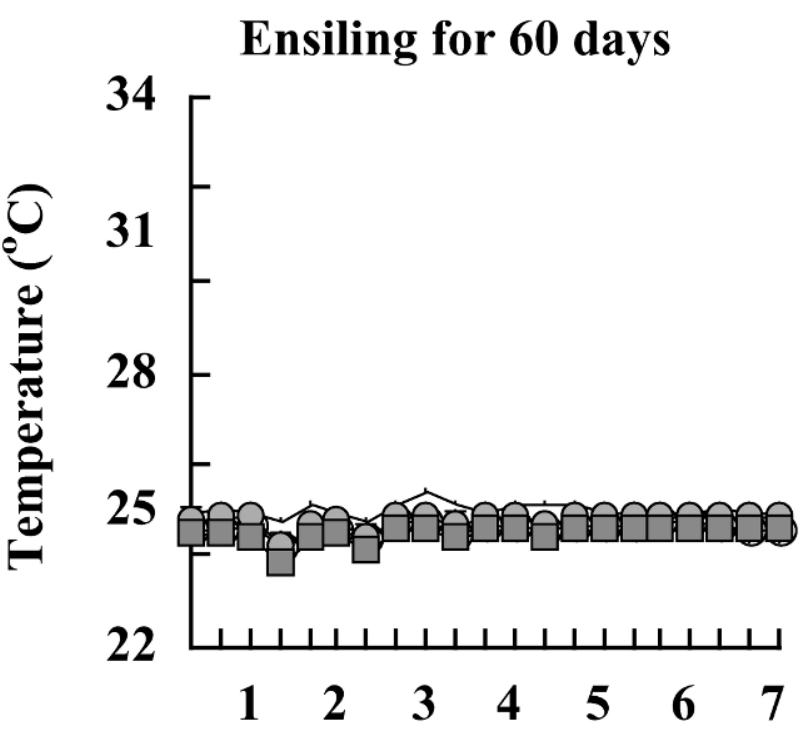

Days after aerobic exposure

Figure 1. Changes in temperature during aerobic deterioration of whole crop corn and a total mixed ration stored in laboratory silos for 10 and 60 days without $(\bigcirc)$ and with inoculation of Lactobacillus casei $(\bigcirc)$ or Lactobacillus buchneri ( $\square$ ). Points indicate mean values of triplicate silages with standard deviations represented by vertical bars. Unbroken lines without any points indicate values for ambient temperatures. 
tulolium silages (Nishino et al., unpublished observations).

High aerobic stability was found in TMR silage regardless of bacterial inoculant and ensiling period. This resistance was also shown previously in untreated TMR silage, although the stability test was conducted only at $60 \mathrm{~d}$ of ensiling, when yeasts were reduced to undetectable level (Nishino et al., 2003b). In this study, the stability was shown even when about $10^{6} \mathrm{cfu} / \mathrm{g}$ of yeasts remained and appeared to be unrelated to the profile of fermentation that varied with inoculation of $L$. casei. Evidence has shown that silages with more than $10^{5}$ $\mathrm{cfu} / \mathrm{g}$ of yeasts are prone to deteriorate on exposure to air (McDonald et al., 1991). This criterion could account for the results of corn silage, but apparently did not suit the results of TMR silage stored for $10 \mathrm{~d}$.

It has been shown that the antifungal activity of silage acids can be better expressed by the amounts of undissociated acids on a water basis (Muck and O'Kiely, 1992). In this respect, total acids were considerably high in TMR silage, and the resistance to aerobic deterioration may be considered as that anticipated. However, the amount of undissociated acids was not necessarily higher in stable TMR silage than in labile corn silage. Therefore, other unidentified factors might be involved in the resistance of TMR silage in the presence of air.

A small amount of 1,2-propanediol was detected in untreated TMR silage when ensiling was prolonged. This agreed with the previous finding, and such untreated TMR silage served as the source of L. buchneri used in the present experiments (Nishino et al., 2003b). These findings suggested that the stability could be ascribed to an activity of L. buchneri that might have dominated over TMR silage by unknown reasons. However, 1,2-propanediol could be determined in aerobically unstable silages (Driehuis et al., 2001), and in this study high stability was achieved even when no 1,2propanediol was determined. Therefore, L. buchneri would not be involved primarily in the stability of untreated TMR silage.

In the present experiments, considerable amounts of 1,2-propanediol accumulated in silage treated with $L$. buchneri. It has been demonstrated that, although once produced by L. buchneri, 1,2-propanediol would not accumulate in silage and be further metabolized to propionic acid and 1-propanol (Driehuis et al., 1999, 2002; Krooneman et al., 2002). When our isolate was inoculated, however, very few silages produced 1-propanol and the content of 1,2-propanediol reached at 7.7\% DM at highest (Nishino et al., unpublished observations). The cause of this difference is not yet known, thereby factors influencing on the activity of $L$. buchneri remain to be investigated.
There have been concerns that use of heterofermentative LAB may result in increased DM loss during ensiling. A number of reports demonstrated significant DM loss due to L. buchneri (Driehuis et al., 1999, 2002), while some other studies did not show the changes (Kung and Ranjit, 2001; Taylor et al., 2002; Nishino et al., 2003a). In this study, the loss appeared to be lowered when TMR mixture was inoculated, indicating that L. buchneri might have benefits in DM recovery when yeasts dominated the fermentation to produce considerable amounts of ethanol.

\section{CONCLUSIONS}

Untreated whole crop corn was well preserved but easily deteriorated after exposure to air. Inoculation with $L$. casei inhibited $\mathrm{NH}_{3}-\mathrm{N}$ production, but the aerobic stability appeared to be further lowered. Yeasts were suppressed when L. buchneri was inoculated, and the stability of corn silage was greatly improved. A TMR silage comprising mainly wet brewers grains also had no butyric acid, but the main fermentation product was ethanol in untreated silage. Inoculation with $L$. casei and L. buchneri decreased the ethanol in TMR silage by inhibiting heterolactic fermentation and yeast growth, respectively. These TMR silages, regardless of treatments, showed considerable resistance to aerobic spoilage, and no heating was observed even when high yeasts $\left(>10^{6} \mathrm{cfu} / \mathrm{g}\right)$ were counted at unloading. It is concluded that inoculation with L. buchneri can be a promising way to inhibit the aerobic spoilage of silage, and that ensiling as a TMR could be an option to preserve wet brewers grains with high stability after exposure to air.

\section{ACKNOWLEDGMENTS}

The authors thank the staff of Tsudaka Livestock Farm, Okayama University, for their help in preparing whole crop corn silage. A part of this study was funded by Morinaga Foundation, Ito Foundation, and Japan Society for the Promotion of Science (no. 15580234).

\section{REFERENCES}

Driehuis, F., S. J. W. H. Oude Elferink, and S. F. Spoelstra. 1999. Anaerobic lactic acid degradation during ensilage of whole crop maize inoculated with Lactobacillus buchneri inhibits yeast growth and improves aerobic stability. J. Appl. Microbiol. 87:583-594.

Driehuis, F., and P. G. van Wikselaar. 2000. The occurrence and prevention of ethanol fermentation in high-dry matter grass silage. J. Sci. Food Agric. 80:711-718.

Driehuis, F., S. J. W. H. Oude Elferink, and P. G. van Wikselaar. 2002. Fermentation characteristics and aerobic stability of grass silage inoculated with Lactobacillus buchneri, with or without homofermentative lactic acid bacteria. Grass Forage Sci. 56:330-343. 
Hara, S., M. Itoh, and Y. Ohyama. 1979. Aerobic deterioration of silages changes in temperature, gas metabolism, heat production and microflora. Jpn. J. Zootech. Sci. 50:549-556.

Krooneman. J., F. Faber, A. C. Alderkamp, S. J. W. H. Oude Elferink, F. Driehuis, I. Cleenwerck, J. Swings, J. C. Gottschal, and M. Vancanneyt. 2002. Lactobacillus diolivorans sp. nov., a 1,2-propanediol-degrading bacterium isolated from aerobically stable maize silage. Int. J. Sys. Evol. Microbiol. 52:639-646.

Kung, L., and N. K. Ranjit. 2001. The effect of Lactobacillus buchneri and other additives on the fermentation and aerobic stability of barley silage. J. Dairy Sci. 84:1149-1155.

McDonald, P., A. R. Henderson, and S. J. E. Heron. 1991. The Biochemistry of Silage. Chalcombe Publications, Welton, Lincoln, UK.

Nishino, N., and S. Uchida. 1999. Laboratory evaluation of previously fermented juice as a fermentation stimulant for lucerne silage. J. Sci. Food Agric. 79:1285-1288.

Nishino, N., M. Yoshida, H. Shiota, and E. Sakaguchi. 2003a. Accumulation of 1,2-propanediol and enhancement of aerobic stability in whole crop maize inoculated with Lactobacillus buchneri. J. Appl. Microbiol. 94:1-8.

Nishino, N., H. Harada, and E. Sakaguchi. 2003b. Evaluation of fermentation and aerobic stability of wet brewers grains ensiled alone or in combination of various feeds as a total mixed ration. J. Sci. Food Agric. 83:557-563.

Oude Elferink, S. J. W. H., J. Krooneman, J. C. Gottschal, S. F. Spoelstra, F. Faber, and F. Driehuis. 2001. Anaerobic conversion of lactic acid to acetic acid and 1,2-propanediol by Lactobacillus buchneri. Appl. Environ. Microbiol. 67:125-132.

Ranjit, N. K., and L. Kung. 2000. The effect of Lactobacillus buchneri, Lactobacillus plantarum, or a chemical preservative on the fermentation and aerobic stability of corn silage. J. Dairy Sci. 83:526-535.

Ranjit, N. K., C. C. Taylor, and L. Kung. 2002. Effect of Lactobacillus buchneri 40788 on the fermentation, aerobic stability and nutritive value of maize silage. Grass Forage Sci. 57:73-81.

Taylor, C. C., N. K. Ranjit, J. A. Mills, J. M. Neylon, and L. Kung. 2002. The effect of treating whole-plant barley with Lactobacillus buchneri 40788 on silage fermentation, aerobic stability, and nutritive value for dairy cows. J. Dairy Sci. 85:1793-1800.

Van Soest, P. J., J. B. Robertson, and B. A. Lewis. 1991. Methods of dietary fiber, neutral detergent fiber and nonstarch polysaccharides in relation to animal nutrition. J. Dairy Sci. 74:3583-3597.

Weinberg, Z. G., G. Szakacs, G. Ashbell, and Y. Hen. 1999. The effect of Lactobacillus buchneri and L. plantarum, applied at ensiling, on the ensiling fermentation and aerobic stability of wheat and sorghum silages. J. Ind. Microbiol. Biotech. 23:218-222.

Weinberg, Z. G., G. Ashbell, Y. Hen, A. Azrieli, G. Szakacs, and I. Filya. 2002. Ensiling whole-crop wheat and corn in large containers with Lactobacillus plantarum and Lactobacillus buchneri. J. Ind. Microbiol. Biotech. 28:7-11.

Woolford, M. K. 1990. The detrimental effects of air on silage. J. Appl. Bacteriol. 68:101-116. 